Extended Abstract

\title{
Recommendations for the Management of Construction and Demolition Waste in Treatment Plants ${ }^{+}$
}

\author{
Auxi Barbudo*, Jesús Ayuso, Angélica Lozano, Manuel Cabrera and Antonio López-Uceda \\ Construction Engineering Area, University of Cordoba, 14071 Cordoba, Spain; ir1ayuje@uco.es (J.A.); \\ angelica.lozano@uco.es (A.L.); manuel.cabrera@uco.es (M.C.); p62louca@uco.es (A.L.-U.) \\ * Correspondence: abarbudo@uco.es; Tel.: +34-957-218-547 \\ + Presented at Environment, Green Technology and Engineering International Conference (EGTEIC 2018), \\ Caceres, Spain, 18-20 June 2018.
}

Published: 18 October 2018

\begin{abstract}
Construction and demolition waste consists approximately of one third waste generated in the European Union. The recycling of this stream waste will provide ecological and sustainable benefits. Recycled aggregates from construction and demolition waste are clearing a path into civil constructions, as substitutes for natural aggregates. The possible applications of recycled aggregates on infrastructure construction projects will depend on the quality of the recycled aggregates mainly. This will be determined by the nature and the origin of the construction and demolition waste, and the treatment system undergone. Hence, this work proposes recommendations for the handling of construction and demolition waste in treatment plants.
\end{abstract}

Keywords: construction and demolition waste; recycled aggregates; waste management; handling; recommendations

\section{Introduction}

Construction and demolition waste $(\mathrm{CDW})$ is any substance or object generated on a construction or demolition site, and whose owner discards or intends to discard [1]. This waste is one third of the total waste generated in the European Union (EU), it is more than 850 million [2]. CDW has been upgraded to a priority waste stream status in the EU. Directive 2008/98/CE, to promote CDW re-use, recycling and other recovery operations, establishes a minimum of $70 \%$ in weight of these activities by 2020. This waste is usually transported to a CDW treatment plant, where it is managed and treated for their subsequent disposal at landfills or reuse as Recycled Aggregate (RA). The mean of recycling rate of the EU members, determined by the percentage of total produced CDW that is processed as recycled aggregate (RA), is over $40 \%$, whereas Spain this recycling rate does not reach $15 \%$ [3].

Several administrations are responsible for the management of CDW, either at the local, regional, national or continental levels. These administrations promulgate acts, laws, and directives. with the aim of minimizing, reusing and recycling the CDW generated, and valorizing of nonrecyclable waste.

However, there is currently many CDW that are being handled inappropriately. It is also noteworthy that project designers and construction managers do not consider in most cases the recycled aggregates of CDW as construction material in their works. Rodriquez-Robles (2015) concluded that, in Spain, one of the obstacles, apart from the administrative theme, is the lack of confidence in the product given the differences between the RA produced in the CDW treatment plants [4]. 
For this purpose, it is necessary to publicize the obligations of each of the agents involved in the management of the CDW and disclose good practices in the management of the CDW that must be carried out in the treatment plants. This paper, which is extracted from a more extensive document [5], intends to address handling recommendations in CDW treatment plants to obtain recycled aggregates (RA) that guarantee enough quality in its implementation.

\section{Methods}

13 authorized treatment plants, located in central Andalusia, were visited to study the optimum CDW treatment system. Hence, samples of the different types of RA produced in each plant were taken and characterized. According to the characterization and the cooperative work with CDW managers, it was established the following proposal for the treatment process of this waste.

\section{Handling Recommendations}

\subsection{Selective Demolition}

Treatment of the CDW should not start in the treatment plant but should be considered from its origin, at the time of deconstruction or demolition. To minimize the amount of CDW that is destined for disposal at landfill, selective demolition should include the dismantling of elements classified as hazardous waste (asbestos elements, plumbing, refrigerants for air conditioning installations, etc.), electrical installations, carpentry, elements with high plaster content, structures, and foundations.

\subsection{Weighing and Classification of the $C D W$}

At the entrance to the plant, the CDW must be weighed using a scale, and classified according to two criteria (Table 1): the nature of the CDW (concrete, mixed and asphalt) and economic effort necessary to carry out cleaning (removal of hazardous waste and improper elements such as plaster, plaster, wood, or glass).

Separating the different fractions by a selective demolition process can result in an increase in the cost of demolition. To compensate this, the CDW treatment plants must offer differentiated fees, depending on the degree of contamination of the CDW in its reception.

Table 1. Classification of the CDW at the entrance and destination.

\begin{tabular}{cccc}
\hline & Clean & Dirty & Very Dirty \\
\hline Concrete & & & \\
Mixed & Storage & Manual cleaning & Disposal at landfill \\
Asphaltic & & & \\
\hline
\end{tabular}

\subsection{Destination of $C D W$ According the Classification}

According to nature of the CDW (concrete, mixed and asphaltic), three storage areas, where the stockpiles will be located, must be arranged. In case that the material is considered clean, it will be discharged directly into its collection area.

In case that the CDW is classified as dirty, a manual cleaning of hazardous elements will be carried out, which will be assigned to an authorized manager. In this way, large size elements will be disposal to landfill. And if the CDW is classified as very dirty, the economic effort to obtain a RA with enough quality to be put on market is too high, so for this reason, it should be destined to disposal at landfill.

\subsection{CDW Treatment Line}

Most of the visited plants, and other plants such as presented by Mas et al. (2012) [6], they had a different treatment line for concrete CDW and mixed CDW. Due to economic considerations, it is 
only considered necessary to have a single CDW treatment line. In the CDW treatment line proposed, up to a maximum of three stages are distinguished, as shown Figure 1.

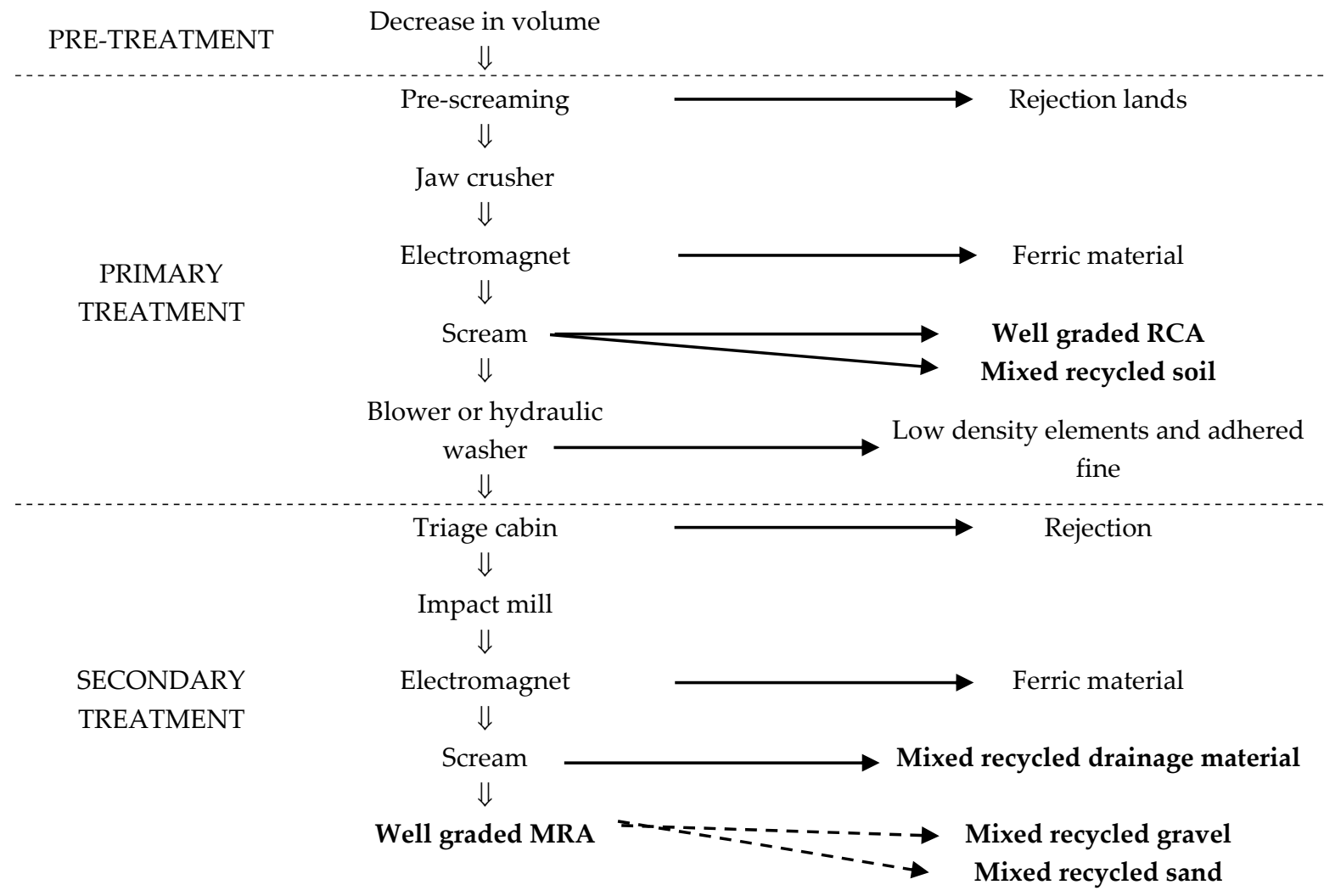

Figure 1. Proposal of CDW treatment line.

\subsubsection{Pre-Treatment}

This phase aims to decrease the volume of those large elements. This is done with a demolishing or vibrating hammer.

\subsubsection{Primary Treatment}

It must include a pre-screening (to remove soils and plaster particles), a crushing by jaw crusher, an electromagnetic magnet (to eliminate steel objects), a screening (of variable size according to demand), and a blower or hydraulic washer (to eliminate low density elements, such as plastics and adhered fine). After this, an all-in aggregate is obtained (of concrete or mixed, depending on the source material).

\subsubsection{Secondary Treatment}

The impurities such as wood, glass, plastics... are eliminated manually through conveyor belts. This process is of great importance to obtain a quality RA. Later, an impact mill should provide RA with a well-graded particle size distribution and a suitable number of fracture faces. After that, it is necessary to have a second electromagnet and place a sieve with one or several sizes. To avoid the formation of dust and loss of material, dust suppressors, such as sprinklers, should be used.

In the case of processing CDW from crushed concrete, this stage is not necessary (Figure 1). A mixed drainage material and a mixed well-graded RA are obtained. The latter has better technical properties than that obtained in the primary treatment (mixed recycled soil). In case that the market demands sand and gravel, they could be produced instead of well-graded RA. 


\subsection{Quality Control System}

Finally, the manufacturer must establish a quality control system in the production of RA, based on EN 13242 standard for their use in civil engineering work and road construction. It specifies the tests to be conducted and their minimum frequency. The manufacturer must establish a production control manual.

\section{Conclusions}

Selective demolition is extremely important for obtaining high quality RA. It should be considered the first step in CDW treatment. Given that it may increase the final price of the RA produced, CDW treatment plants must offer differentiated fees, depending on the degree of contamination of the CDW in its reception.

An appropriate treatment design is necessary. In the case of CDW from crushed concrete, it should consist of a pre-treatment and a primary treatment. And in the case of mixed CDW, a secondary treatment should be added. In addition, a periodic quality control of the material produced is crucial.

Author Contributions: A.B. and J.A. have actively worked on the project and developed as authors a "Guide to Good Practices" from which this communication is extracted and reviewed this work. A.L., M.C. and A.L.-U. have analyzed the data, worked in the preparation of the communication and write the full paper.

Acknowledgments: The authors would like to thank the ERDF of the European Union and the Public Works Agency and Regional Ministry of Public Works and Housing of the Regional Government of Andalusia for financial support via the project "Applications of recycled aggregates from construction and demolition waste (CDW) for the sustainable development of road infrastructure in central areas of Andalusia" from the "20072013 ERDF Operational Program for Andalusia. Thanks also to Association of Construction Waste Management Companies and Demolition of Andalusia (AGRECA) and the Center for Studies of Materials and Works Control SA (CEMOSA) (no funds for covering the costs to publish in open Access).

Conflicts of Interest: The authors declare no conflict of interest. The funding sponsors that have participated in the design of the study (Regional Ministry of Public Works and Housing of the Regional Government of Andalusia) have been already indicated in the Acknowledgments. In any case, the funding sponsors don't have interest or benefit on the results obtained.

\section{References}

1. Huang, W.L.; Lin, D.H.; Chang, N.B.; Lin, K.S. Recycling of construction and demolition waste via a mechanical sorting process. Resour. Conserv. Recycl. 2002, 37, 23-37.

2. European Commission, Eurostat. Waste Generation by Economic Activities and Households. 2014. Available online: http://ec.europa.eu/eurostat/statistics-explained/index.php/Waste_statistics (accessed on 29 May 2018).

3. European Commission (DG ENV). Final Report Task 2: Service Contract on Management of Construction and Demolition Waste Prepared by Bio Intelligent Service. 2011. Available online: http://ec.europa.eu/ environment/waste/pdf/2011_CDW_Report.pdf (accessed on 26 May 2018).

4. Rodríguez-Robles, D.; García-González, J.; Juan-Valdés, A.; Morán-del Pozo, J.M.; Guerra-Romero, M.I. Overview regarding construction and demolition waste in Spain. Environ. Technol. 2015, 36, 1-11.

5. Public Works Agency and Regional Ministry of Public Works and Housing of the Regional Government of Andalusia. Guide to Good Practices; UCOPress, Editorial Universidad de Córdoba: Cordoba, Spain, 2015. Available online: http://www.aridosrcdandalucia.es/rcd/guia-de-buenas-practicas/ (accessed on 30 May 2018). (In Spanish)

6. Mas, B.; Cladera, A.; Del Olmo, T.; Pitarch, F. Influence of the amount of mixed recycled aggregates on the properties of concrete for non-structural use. Constr. Build. Mater. 2012, 27, 612-622. 